\title{
Fixed points for Quasi contraction maps on complete metric spaces
}

Amalendu Choudhury ${ }^{\mathrm{a}}, \mathrm{T}$. Som ${ }^{\mathrm{b}, *}$

a Department of Mathematics and Statistics Haflong Govt. College, Haflong-788819, Dima Hasao, Assam, India.

${ }^{b}$ Department of Mathematical Sciences, Indian Institute of Technology (Banaras Hindu University), Varanasi -221005, India.

\begin{abstract}
The present paper deals with unique fixed point results for quasi contraction mappings on a metric space satisfying some generalized inequality conditions in first section and unique common fixed point result for asymptotically regular mappings of certain type and satisfying a generalized contraction condition in another section. The results obtained generalize the earlier results of Fisher (1979), Hardy and Roger (1973) and others in turn. (C)2016 All rights reserved.
\end{abstract}

Keywords: Quasi contraction, complete metric space, asymptotically regular, generalized contraction, fixed point.

2010 MSC: 47H09, 54E50, 47H10.

\section{Introduction}

Definition $1.1([1])$. A mapping $T$ on a metric space $X$ into itself is said to be a quasi - contraction if and only if there exist a number $c$, with $0 \leq \mathrm{c}<1$, such that

$$
d(T x, T y) \leq c \max \{d(x, y) d(x, T x), d(y, T y), d(x, T y), d(y, T x)\}
$$

for all $x, y$ in $X$.

Definition $1.2([1]) . X$ is said to be $T$ orbitally complete if and only if every Cauchy sequence which is contained in the sequence $\left\{x, T x, \ldots, T^{n} x, \ldots\right\}$ for some $x$ in $X$ converges in $X$.

*Corresponding author

Email addresses: amalendu_choudhury@yahoo.com (Amalendu Choudhury), tsom.apm@iitbhu.ac.in (T. Som) 
He then established the following basic results for such mappings:

Theorem 1.3. Let $T$ be a quasi contraction on the metric space $X$ into itself and let $X$ be $T$ orbitally complete. Then $T$ has a unique fixed point in $X$.

Theorem 1.4. Let $T$ be a continuous mapping on the complete metric space $X$ into itself satisfying the inequality:

$$
\left.d\left(T^{p} x, T^{q} y\right) \leq c \max \left\{d\left(T^{r} x, T^{s} y\right), d\left(T^{r} x, T^{\gamma^{\prime}} x\right), d\left(T^{s} y, T^{s^{\prime}} y\right)\right\}: 0 \leq r, r^{\prime}<p \text { and } 0 \leq s, s^{\prime} \leq q\right\}
$$

for all $x$, $y$ in $X$, where $0 \leq c<1$, for some positive integer $p$ and $q$, then $T$ has a unique fixed point. For a continuous quasi contraction mapping the following result is proved.

Theorem 1.5. Let $T$ be a quasi contraction on the metric space $X$ into itself and let $T$ be continuous. Then $T$ has a unique fixed point in $X$.

It may be noted that in case when $\mathrm{T}$ is a quasi contraction for which $q$ (or $p)=1$, the continuity condition of $T$ is unnecessary. We then have,

Theorem 1.6. Let $T$ be a mapping on the complete metric space $X$ into itself satisfying the inequality

$$
\left.d\left(T^{p} x, T y\right) \leq c \max \left\{d\left(T^{r} x, T^{s} y\right), d\left(T^{r} x, T^{\gamma^{\prime}} x\right), d\left(T^{s} y, T^{s^{\prime}} y\right)\right\}: 0 \leq r, r^{\prime}<p \text { and } s=0,1\right\}
$$

for all $x, y$ in $X$, where $0 \leq c<1$, for some positive integer $p$. Then $T$ has a unique fixed point in $X$.

In the next section we obtain some fixed point results for such mappings, which satisfy a more general inequality conditions.

\section{Results for Quasi contraction mappings}

Theorem 2.1. Let $T$ be a quasi contraction on the complete metric space $X$ into itself satisfying the inequality

$$
d\left(T p x, T^{q} y\right) \leq c \max \left\{d\left(T^{\gamma} x, T^{s} y\right), d\left(T^{\gamma} x, T^{\gamma^{\prime}} x\right), d\left(T^{s} y, T^{s^{\prime}} y\right), d\left(T^{\gamma^{\prime}} x, T^{s^{\prime}} y\right)\right\}
$$

$0 \leq \gamma, \gamma<p$ and $0 \leq s, s^{\prime} \leq q$ for all $x, y$ in $X$ where $0 \leq c<1$ and for some fixed positive integers $p$ and $q$. Then $T$ has a unique fixed point in $X$.

Proof. Without loss of generality we assume that $\frac{1}{2} \leq \mathrm{c}<1$. Inequality (2.1) will still hold but we will then have $\frac{c}{1-c} \geq 1$. We assume that $\mathrm{p} \geq \mathrm{q}$. Let for an arbitrary point $\mathrm{x}$ in $\mathrm{X}$ the sequence $\left\{\mathrm{T}^{n} \mathrm{x}\right\}$ is unbounded.

Then the sequence $\left\{d\left(T^{n} x, T^{q} x\right): n=1,2, \ldots\right\}$ is unbounded and so there exists an integer $n$ such that

$$
\left(T^{n} x, T^{q} x\right)>\left(\frac{c}{1-c}\right) \max \left\{d\left(T^{i} x, T^{q} x\right): 0 \leq i<p\right\} .
$$

Suppose $\mathrm{n}$ is the smallest such integer satisfying the above inequality and since $\frac{c}{1-c} \geq 1$, we must have $n>p \geq q$. 
Thus

$$
\begin{aligned}
d\left(T^{n} x, T^{q} x\right) & >\left(\frac{c}{1-c}\right) \max \left\{d\left(T^{i} x, T^{q} x\right): 0 \leq i<p\right\} \\
& \geq \max \left\{d\left(T^{\gamma} x, T^{q} x\right): 0 \leq \gamma<n\right\} .
\end{aligned}
$$

It now follows from inequality 2.2 that

$$
\begin{aligned}
(1-c) d\left(T^{n} x, T^{q} x\right) & >c \max \left\{d\left(T^{i} x, T^{q} x\right): 0 \leq i \leq p\right\} \\
& \geq c \max \left\{d\left(T^{i} x, T^{\gamma} x\right)-d\left(T^{\gamma} x, T^{q} x\right): 0 \leq i \leq p \text { and } 0 \leq \gamma<n\right\} \\
& \geq c \max \left\{d\left(T^{i} x, T^{\gamma} x\right)-d\left(T^{n} x, T^{q} x\right): 0 \leq i \leq p \text { and } 0 \leq \gamma<n\right\}
\end{aligned}
$$

and so

$$
d\left(T^{n} x, T^{q} x\right)>c \max \left\{d\left(T^{i} x, T^{\gamma} x\right): 0 \leq i \leq p \text { and } 0 \leq \gamma<n\right\} .
$$

We will now prove that

$$
d\left(T^{n} x, T^{q} x\right)>c \max \left\{d\left(T^{i} x, T^{\gamma} x\right): 0 \leq i, \gamma<n\right\} .
$$

For, if not so then we have

$$
d\left(T^{n} x, T^{q} x\right) \leq c \max \left\{d\left(T^{i} x, T^{\gamma} x\right): 0 \leq i, \gamma<n\right\}
$$

i.e.,

$$
d\left(T^{n} x, T^{q} x\right) \leq c \max \left\{d\left(T^{i} x, T^{\gamma} x\right): p<i, \gamma<n\right\} .
$$

In view of inequality (2.4), we can apply inequality (2.1) indefinitely to inequality $(2.6)$, since whenever terms of the form $\mathrm{d}\left(\mathrm{T}^{i} \mathrm{x}, \mathrm{T}^{\gamma} \mathrm{x}\right)$ appear with $0 \leq i \leq \mathrm{p}$, they can be omitted because of inequality (2.4). This means that

$$
d\left(T^{n} x, T^{q} x\right) \leq c^{k} \max \left\{d\left(T^{i} x, T^{\gamma} x\right): p<i, \gamma<n\right\}
$$

for $\mathrm{k}=1,2, \ldots$ and on letting limit $\mathrm{k}$ tending to infinity it follows that $\mathrm{d}\left(\mathrm{T}^{n} \mathrm{x}, \mathrm{T}^{q} \mathrm{x}\right)=0$, which gives a contradiction. So inequality (2.5) now follows. However, on using inequality (2.1), we now have

$$
\begin{gathered}
d\left(T^{n} x, T^{q} x\right) \leq c \max \left\{d\left(T^{\gamma} x, T^{s} x\right), d\left(T^{\gamma} x, T^{\gamma^{\prime}} x\right), d\left(T^{s} x, T^{s^{\prime}} x\right),\left(T^{\gamma^{\prime}} x, T^{s^{\prime}} y\right)\right. \\
\left.\quad: n-p \leq \gamma, \gamma^{\prime} \leq n \text { and } 0 \leq s, s^{\prime} \leq q\right\} \\
\leq c \max \left\{d\left(T^{\gamma} x, T^{s} x\right): 0 \leq \gamma, s \leq n\right\}
\end{gathered}
$$

which is impossible, because of inequality (2.5). This contradiction further implies that the sequence $\left\{\mathrm{T}^{n} \mathrm{x}: \mathrm{n}=1,2, \ldots\right\}$ must be bounded.

Now taking

$$
M=\sup \left\{d\left(T^{\gamma} x, T^{s} x\right): \gamma, s=0,1,2, \ldots\right\}<\infty
$$

and then for arbitrary $\epsilon>0$, choosing $\mathrm{N}$ such that $\mathrm{c}^{N} \mathrm{M}<\epsilon$, it follows that for $\mathrm{m}, \mathrm{n} \geq N \max \{\mathrm{p}, \mathrm{q}\}$ and on using inequality (2.1) $\mathrm{N}$ times we get

$$
d\left(T^{m} x, T^{n} x\right) \leq c^{N} M<\epsilon .
$$

Thus the sequence $\left\{\mathrm{T}^{n} \mathrm{x}: \mathrm{n}=1,2, \ldots\right\}$ is a Cauchy sequence in the complete metric space $X$ and so has a limit $z$ in $X$. Since $T$ is continuous it follows that $T z=z$ and so $z$ is a fixed point of $T$. The uniqueness of $z$ follows easily from the inequality (2.1). This completes the proof of the Theorem. 
Our next generalization goes as follows.

Theorem 2.2. Let $T$ be a mapping on the complete metric space $X$ into itself satisfying the inequality

$$
d\left(T^{p} x, T y\right) \leq c \max \left\{d\left(T^{\gamma} x, T^{s} y\right), d\left(T^{\gamma} x, T^{\gamma^{\prime}} x\right), d(y, T y), d\left(T^{\gamma^{\prime}} x, T y\right): 0 \leq \gamma, \gamma^{\prime} \leq p \text { and } s=0,1\right\}
$$

for all $x, y$ in $X$ where $0 \leq c<1$, for some fixed positive integer $p$. Then $T$ has a unique fixed point in $X$.

Proof. Let $x$ be an arbitrary point in $X$. Then, as in the proof of 2.1 , the sequence $\left\{T^{n} x\right\}$ is a Cauchy sequence in the complete metric space $X$ and so has a limit $z$ in $X$. For $\mathrm{n} \geq \mathrm{p}$, we now have

$$
\left(T^{n} x, T z\right) \leq c \max \left\{d\left(T^{\gamma} x, T^{s} x\right), d\left(T^{\gamma} x, T^{\gamma^{\prime}} x\right), d(z, T z),\left(T^{\gamma^{\prime}} x, T z\right): n-p \leq \gamma, \gamma^{\prime} \leq n a n d s=0,1\right\} .
$$

Taking $\mathrm{n}$ tends to infinity it follows that

$$
\begin{aligned}
d(z, T z) & \leq c \max \left\{d\left(z, T^{s} z\right): s=0,1\right\} \\
& =c d(z, T z) .
\end{aligned}
$$

Since $c<1$, we see that $\mathrm{z}$ is a fixed point of $\mathrm{T}$. This completes the proof of the theorem.

The following corollary is immediate when $\mathrm{p}=1$.

Corollary 2.3. Let $T$ be a mapping on the complete metric space $X$ into itself satisfying the inequality

$$
d(T x, T y) \leq c \max \{d(x, y), d(x, T x), d(y, T y), d(x, T y), d(y, T x)\}
$$

for all $x, y$ in $X$, where $0 \leq c<1$. Then $T$ has a unique fixed point in $X$.

We now note that the condition that $\mathrm{T}$ be continuous when $\mathrm{p}, \mathrm{q} \geq 2$ is necessary in Theorem 1.5 This is easily seen by considering $\mathrm{X}$ be the closed interval $[0,1]$ with the usual metric. Define a discontinuous mapping $\mathrm{T}$ on $\mathrm{X}$ by

$$
T x= \begin{cases}1 & \text { if } x=0 \\ \frac{1}{2} x & \text { if } x \neq 0\end{cases}
$$

We then have

$$
d\left(T^{p} x, T^{q} y\right)=\frac{1}{2} d\left(T^{p-1} x, T^{q-1} y\right)
$$

for all $\mathrm{x}, \mathrm{y}$ in $\mathrm{X}$ and so $\mathrm{T}$ is a quasi contraction with $c=\frac{1}{2}$. $\mathrm{T}$ however has no fixed point. We now prove a fixed point theorem on a compact metric space.

Theorem 2.4. Let $T$ be a continuous mapping on the compact metric space $X$ into itself satisfying the inequality

$$
\begin{gathered}
d\left(T^{p} x, T^{q} y\right)<\max \left\{d\left(T^{\gamma} x, T^{s} y\right), d\left(T^{\gamma} x, T^{\gamma^{\prime}} x\right), d\left(T^{s} y, T^{s^{\prime}} y\right), d\left(T^{\gamma^{\prime}} x, T^{s^{\prime}} y\right)\right. \\
\left.: 0 \leq \gamma, \gamma^{\prime} \leq p \text { and } 0 \leq s, s^{\prime} \leq q\right\}
\end{gathered}
$$

for all $x, y$ in $X$ for which the right hand side of the inequality is positive. Then $T$ has a unique fixed point in $X$. 
Proof. Suppose first of all that $\mathrm{T}$ is a quasi contraction. The result then follows from Theorem 2.1 If $T$ is not a quasi- contraction and if $\left\{\mathrm{c}_{n}: \mathrm{n}=1,2, \ldots\right\}$ is a monotonically increasing sequence of numbers converging to 1 , then there must exist sequences. $\left\{\mathrm{x}_{n}\right\}$ and $\left\{\mathrm{y}_{n}\right\}$ in $X$ such that

$$
\begin{gathered}
d\left(T^{p} x_{n}, T^{q} y_{n}\right)>c_{n} \max \left\{d\left(T^{\gamma} x_{n}, T^{s} y_{n}\right), d\left(T^{\gamma} x_{n}, T^{\gamma^{\prime}} x_{n}\right), d\left(T^{s} y_{n}, T^{s^{\prime}} y_{n}\right), d\left(T^{\gamma^{\prime}} x_{n}, T^{s^{\prime}} y_{n}\right):\right. \\
\left.0 \leq \gamma, \gamma^{\prime} \leq \operatorname{pand} 0 \leq s, s^{\prime} \leq q\right\}
\end{gathered}
$$

for $\mathrm{n}=1,2, \ldots$ Since $\mathrm{X}$ is compact, there exist subsequences $\left\{\mathrm{x}_{n k}: \mathrm{k}=1,2, ..\right\}$ and $\left\{\mathrm{y}_{n k}: \mathrm{k}=1\right.$, $2, .$.$\} of \left\{\mathrm{x}_{n}\right\}$ and $\left\{\mathrm{y}_{n}\right\}$ converging to $\mathrm{x}$ and $\mathrm{y}$, respectively. We then have

$$
\begin{gathered}
d\left(T^{p} x_{n k}, T^{q} y_{n k}\right)>c_{n k} \max \left\{d\left(T^{\gamma} x_{n k}, T^{s} y_{n k}\right), d\left(T^{\gamma} x_{n k}, T^{\gamma^{\prime}} x_{n k}\right), d\left(T^{s} y_{n k}, T^{s^{\prime}} y_{n k}\right), d\left(T^{\gamma^{\prime}} x_{n k}, T^{s^{\prime}} y_{n k}\right):\right. \\
\left.0 \leq \gamma, \gamma^{\prime} \leq \operatorname{pand} 0 \leq s, s^{\prime} \leq q\right\}
\end{gathered}
$$

for $\mathrm{k}=1,2, \ldots$ Since $T$ is continuous, taking limit as $k$ tends to infinity, we get

$$
\begin{gathered}
d\left(T^{p} x, T^{q} y\right) \geq \max \left\{d\left(T^{\gamma} x, T^{s} y\right), d\left(T^{\gamma} x, T^{\gamma^{\prime}} x\right), d\left(T^{s} y, T^{s^{\prime}} y\right), d\left(T^{\gamma^{\prime}} x, T^{s^{\prime}} y\right):\right. \\
\left.0 \leq \gamma, \gamma^{\prime} \leq \operatorname{pand} 0 \leq s, s^{\prime} \leq q\right\}
\end{gathered}
$$

which leads to a contradiction unless $\mathrm{x}=\mathrm{y}=\mathrm{Tx}$. Thus $\mathrm{x}$ is a fixed point of $\mathrm{T}$. The uniqueness of $\mathrm{x}$ follows easily. This completes the proof of the theorem.

When $\mathrm{p}=\mathrm{q}=1$, we have the following corollary:

Corollary 2.5. Let $T$ be a continuous mapping of the compact metric space $X$ into itself satisfying the inequality

$$
d(T x, T y)<\max \{d(x, y), d(x, T x), d(y, T y), d(x, T y), d(y, T x)\}
$$

for all $x, y$ in $X$ for which the right hand side of the inequality is positive. Then $T$ has an unique fixed point.

\section{A fixed point result for generalized contraction}

In this section we prove common fixed point theorems with the help of sequences which are not necessarily obtained as a sequence of iterates of mappings under consideration. The mappings are asymptotically regular of certain nature mentioned below. The result obtained generalizes a result due to Hardy and Roger [3].

Definition 3.1. Let $A$ and $B$ be two self mappings on $X$ and $\left\{x_{n}\right\}$ a sequence in $X$. Then the sequence $\left\{\mathrm{x}_{n}\right\}$ is said to be asymptotically A-regular with respect to B if

$$
L t_{n \rightarrow \infty} d\left(B x_{n}, A x_{n}\right)=0, \text { when B is identity map. }
$$

Definition 3.2. Let $\mathrm{f}$ and $\mathrm{g}$ be two self mappings on $\mathrm{X}$. Then the pair $\{\mathrm{f}, \mathrm{g}\}$ is said to be a weakly commuting pair if $d(f g x, g f x) \leq d(g x, f x)$ for all $\mathrm{x} \in \mathrm{X}$.

Theorem 3.3. Let $(X, d)$ be a complete metric space. Let $A, B, S, T$ be four self mappings of $X$ satisfying the following conditions: 
(a) $d(S x, T y) \leq a_{1} d(S x, A x)+a_{2} d(T y, B y)+a_{3} d(S x, B y)+a_{4} d(T y, A x)+a_{5} d(A x, B y)$ for all $x, y \in X$ where $a_{i}(i=1,2,3,4,5)$ are non negative real and $\max \left\{\left(a_{2}+a_{4}\right),\left(a_{3}+a_{4}+a_{5}\right)\right\}<$ 1 ,

(b) $A$ and $B$ are continuous,

(c) $\{A, S\}$ and $\{B, T\}$ are weakly commuting pairs,

(d) there exists a sequence which is asymptotically $S$-regular as well as $T$-regular with respect to $A$ and $B$.

Then $A, B, S$, T have a unique common fixed point.

Proof : Let $\left\{\mathrm{x}_{n}\right\}$ be a sequence as described in (b). Then using (a) we get

$$
\begin{aligned}
d\left(A x_{n}, B x_{m}\right) \leq & d\left(A x_{n}, S x_{n}\right)+d\left(S x_{n}, T x_{m}\right)+d\left(T x_{m}, B x_{m}\right) \\
\leq & d\left(A x_{n}, S x_{n}\right)+a_{1} d\left(S x_{n}, A x_{n}\right)+a_{2} d\left(T x_{m}, B x_{m}\right)+a_{3} d\left(S x_{n}, B x_{m}\right) \\
& +a_{4} d\left(T x_{m}, A x_{n}\right)+a_{5} d\left(A x_{n}, B x_{m}\right)+d\left(T x_{m}, B x_{m}\right) \\
\leq & d\left(A x_{n}, S x_{n}\right)+a_{1} d\left(S x_{n}, A x_{n}\right)+a_{2} d\left(T x_{m}, B x_{m}\right)+a_{3}\left[d\left(S x_{n}, A x_{n}\right)+d\left(A x_{n}, B x_{m}\right)\right] \\
& +a_{4}\left[d\left(T x_{m}, B x_{m}\right)+d\left(B x_{m}, A x_{n}\right)\right]+a_{5} d\left(A x_{n}, B x_{m}\right)+d\left(T x_{m}, B x_{m}\right)
\end{aligned}
$$

Therefore, $\mathrm{d}\left(\mathrm{Ax}_{n}, \mathrm{Bx}_{m}\right) \leq \frac{1+a_{1}+a_{3}}{1-a_{3}-a_{4}-a_{5}} \mathrm{~d}\left(\mathrm{Ax}_{n}, \mathrm{Sx}_{n}\right)+\frac{1+a_{2}+a_{4}}{1-a_{3}-a_{4}-a_{5}} \mathrm{~d}\left(\mathrm{Tx}_{m}, \mathrm{Bx} \mathrm{x}_{m}\right)$. This shows that $\left\{A x_{n}\right\}$ is a Cauchy sequence. Let $\lim _{n} \rightarrow \infty A x_{n}=z=\lim _{n} \rightarrow \infty B x_{m}$. Then it follows that $\lim _{n} \rightarrow \infty S x_{n}=$ $z=\lim _{n} \rightarrow \infty T x_{m}$. By virtue of the continuity of $\mathrm{A}$ and $\mathrm{B}$, we find that

$$
A^{2} x_{n} \rightarrow A z, A S x_{n} \rightarrow A z a n d B^{2} x_{m} \rightarrow B z, B T x_{m} \rightarrow B z .
$$

We shall show that

$$
S A x_{n} \rightarrow A z \text { and } T B x_{m} \rightarrow B z \text {. }
$$

For this, consider the inequality,

$$
\begin{aligned}
d\left(S A x_{n}, A z\right) & \leq d\left(S A x_{n}, A S x_{n}\right)+d\left(A S x_{n}, A z\right) \\
& \leq d\left(A x_{n}, S x_{n}\right)+d\left(A S x_{n}, A z\right),
\end{aligned}
$$

which shows that $\mathrm{SAx}_{n} \rightarrow \mathrm{Az}$.

Similarly,

$$
d\left(T B x_{m}, B z\right) \leq d\left(T B x_{m}, B T x_{m}\right)+d\left(B T x_{m}, B z\right) \leq d\left(B x, T x_{m}\right)+d\left(B T x_{m}, B z\right),
$$

which shows that $\mathrm{TBx}_{m} \rightarrow \mathrm{Bz}$.

Now,

$$
\begin{aligned}
d(A z, T z) \leq & d\left(A z, S A x_{n}\right)+d\left(S A x_{n}, T z\right) \\
\leq & d\left(A z, S A x_{n}\right)+a_{1} d\left(S A x_{n}, A^{2} x_{n}\right)+a_{2} d(T z, A z) \\
& +a_{3} d\left(S A x_{n}, A z\right)+a_{4} d\left(T z, A^{2} x_{n}\right)+a_{5} d\left(A^{2} x_{n}, A z\right) .
\end{aligned}
$$

Taking limit as n tending to infinity, we get

$$
d(A z, T z) \leq\left(a_{2}+a_{4}\right) d(A z, T z)
$$


and hence $\mathrm{Az}=\mathrm{Tz}$. Similarly we can show that $\mathrm{Bz}=\mathrm{Sz}$.

Further

$$
\begin{aligned}
d\left(S A x_{n}, T B x_{m}\right) \leq & a_{1} d\left(S A x_{n}, A^{2} x_{n}\right)+a_{2} d\left(T B x_{m}, B^{2} x_{m}\right)+a_{3} d\left(S A x_{n}, B^{2} x_{m}\right) \\
& +a_{4} d\left(T B x_{m}, A^{2} x_{n}\right)+a_{5} d\left(A^{2} x_{n}, B^{2} x_{m}\right) .
\end{aligned}
$$

On taking limits we have

$$
\begin{aligned}
d(A z, B z) & \leq a_{1} d(A z, A z)+a_{2} d(B z, B z)+a_{3} d(A z, B z)+a_{4} d(B z, A z)+a_{5} d(A z, B z) \\
& \leq\left(a_{3}+a_{4}+a_{5}\right) d(A z, B z)
\end{aligned}
$$

i.e. $\left(1-\mathrm{a}_{3}-\mathrm{a}_{4}-\mathrm{a}_{5}\right) \mathrm{d}(\mathrm{Az}, \mathrm{Bz}) \leq 0$. So, $A z=B z$.

Hence $A z=B z=S z=T z$.

Now consider,

$$
d\left(S x_{n}, T z\right) \leq a_{1} d\left(S x_{n}, A x_{n}\right)+a_{2} d(T z, B z)+a_{3} d\left(S x_{n}, B z\right)+a_{4} d\left(T z, A x_{n}\right)+a_{5} d\left(A x_{n}, B z\right) .
$$

As limit $\mathrm{n} \rightarrow \infty$,we have

$$
d(z, T z) \leq a_{1} d(z, z)+a_{2} d(T z, T z)+a_{3} d(z, T z)+a_{4} d(T z, z)+a_{5} d(z, T z)
$$

or

$$
d(z, T z) \leq\left(a_{3}+a_{4}+a_{5}\right) d(z, T z)<d(z, T z)
$$

which implies that $\mathrm{z}=\mathrm{Tz}$. Thus $\mathrm{z}$ is a common fixed points of $\mathrm{A}, \mathrm{B}, \mathrm{S}$ and $\mathrm{T}$.

In order to prove the uniqueness of common fixed point. Let $z_{1}$ and $z_{2}$ be any two distinct common fixed points of $\mathrm{A}, \mathrm{B}, \mathrm{S}$ and $\mathrm{T}$. Then

$$
\begin{aligned}
d\left(z_{1}, z_{2}\right)= & d\left(S z_{1}, T z_{2}\right) \leq d\left(S z_{1}, A z_{1}\right)+a_{2} d\left(T z_{2}, B z_{2}\right)+a_{3} d\left(S z_{1}, B z_{2}\right) \\
& +a_{4} d\left(T z_{2}, A z_{1}\right)+a_{5} d\left(A z_{1}, B z_{2}\right) \\
= & \left(a_{3}+a_{4}+a_{5}\right) d\left(z_{1}, z_{2}\right)<d\left(z_{1}, z_{2}\right) .
\end{aligned}
$$

Therefore, $\mathrm{z}_{1}=\mathrm{z}_{2}$. This completes the proof.

\section{References}

[1] B. Fisher, Quasi contractions on metric spaces, Pro. Amer. Math. Soc., 75 (1979), 321-325. 1.1, 1.2

[2] K. Goebel, W. A. Kirk, T. N. Shimi, A fixed point theorem in uniformly convex spaces, Bull. Math. Ital., 7 (1973), 67-75.

[3] D. E. Hardy, T. D. Rogers, A generalization of a fixed point theorem of Reich, Canad. Math. Bull., 16 (1973), 201-206. 3

[4] G. Jungck, Commuting mappings and fixed points, Amer. Math. Monthly, 83 (1976), 261-263.

[5] R. N. Mukherjee, Common fixed points of some nonlinear mappings, Ind. J. Pure appl. Math., 12 (1981), 930-933.

[6] B. E. Rhoades, A comparison of various definitions of contractive maps", Trans. Amer. Math. Soc., 226 (1977), 257-290. 